\title{
Equilibrium, kinetic and thermodynamic studies on methylene blue ad- sorption by Trichosanthes kirilowii Maxim shell activated carbon
}

\author{
Yuqi Wang, Yanhui Li", Heng Zheng \\ Qingdao University, College of Mechanical and Electrical Engineering, State Key Laboratory of Bio-fibers and Eco-textiles, \\ Qingdao 266071, China. \\ "Corresponding author: e-mail: liyanhui537@163.com
}

\begin{abstract}
New kind of adsorbent was produced from Trichosanthes kirilowii Maxim shell. The $\mathrm{KOH}$ activation technology for preparation of Trichosanthes kirilowii Maxim shell activated carbon $\left(\mathrm{TKMC}_{\mathrm{K}}\right)$ was optimized. Using methylene blue as the sample adsorbate, the adsorption behavior was systematically investigated in terms of the activation agent and temperature, the adsorption temperature and time, the initial adsorbate $\mathrm{pH}$ and concentration, as well as the dosage of adsorbent. Surface physical morphology of the $\mathrm{TKMC}_{\mathrm{K}}$ prepared was observed by scanning electron microscopy (SEM), while the functional groups were determined with Fourier transform infrared (FTIR) spectra. Kinetic studies indicated that the adsorption process was more consistent with the pseudo-second-order kinetic. Both Langmuir and Freundlich isotherms were employed to fit the adsorption data at equilibrium, with the former giving a maximum adsorption capacity of $793.65 \mathrm{mg} / \mathrm{g}$ at $323 \mathrm{~K}$. BET surface area of as-prepared $\mathrm{TKMC}_{\mathrm{K}}$ was $657.78 \mathrm{~m}^{2} / \mathrm{g}$.
\end{abstract}

Keywords: Trichosanthes kirilowii Maxim shell; Biomass; Activated Carbon; Adsorption; Methylene Blue.

\section{INTRODUCTION}

Discharge of dyes and pigments exists extensively in a variety of industries, especially the fields of dye manufacturing and textile finishing ${ }^{1}$. Most of them are intrinsically toxic and can be the direct inducement of allergic dermatitis, skin irritation, mutation and even cancers $^{2}$. Given that, dye removal as a wastewater treatment technique becomes the major environmental interest of researchers all over the world these days.

In order to treat the dye effluents, several approaches have been widely used in wastewater treatment field, such as electrochemical ${ }^{3}$, membrane process ${ }^{4}$, chemical oxidation $^{5}$ and adsorption ${ }^{6}$. Compared with other methods, the activated carbon adsorption process is more convenient and efficient ${ }^{7,8}$. Activated carbon used as adsorbent is getting more popular for adsorption treatments. In recent years, the adsorption of dye has been explored by biomass activated carbon such as periwinkle shells activated carbon ${ }^{9}$, hazelnut husk activated carbon ${ }^{10}$, physic seed hull activated carbon ${ }^{11}$, green coconut mesocarp activated carbon ${ }^{12}$, palm kernel shell activated carbon ${ }^{13}$, cashew nut shell activated carbon ${ }^{14}$, oil palm ash activated carbon ${ }^{15}$, pentace species sawdust activated carbon ${ }^{16}$, and walnut shells activated carbon ${ }^{17}$.

Trichosanthes kirilowii Maxim is a perennial herb of the cucurbitaceae family. It has been widely planted because of strong stability and simplicity to manage. There are a few studies in which Trichosanthes kirilowii Maxim shells (TKMS) were employed as the precursors to produce Trichosanthes kirilowii Maxim shell activated carbon (TKMC). In this contribution, the potential of TKMC to remove aqueous pigments through carbonization activation processes was detailedly assessed, with methylene blue serving as the target adsorbate and various metal salts $\left(\mathrm{ZnCl}_{2}, \mathrm{NaOH}\right.$ and $\left.\mathrm{KOH}\right)$ as the activation reagents. A series of adsorption experiments were conducted to investigate the effects of contact time, initial concentration, temperature, $\mathrm{pH}$, adsorbent doses, kinetic, isotherm and thermodynamic analysis.
Results showed that the TKMC obtained in this study could be a potential adsorbent candidate for effective water purification.

\section{MATERIAL AND METHODS}

\section{Material}

Trichosanthes kirilowii Maxim shell (TKMS) was purchased from local vegetable market. After rinsed by distilled water for impurity removal, TKMS was transferred into a drying oven and kept for $24 \mathrm{~h} .5 \mathrm{~g}$ of TKMS was soaked in three different types of activation reagent solution $\left(50 \mathrm{~mL} \mathrm{ZnCl}_{2}, 50 \mathrm{~mL} \mathrm{NaOH}\right.$ and $\left.50 \mathrm{~mL} \mathrm{KOH}\right)$ for $48 \mathrm{~h}$, respectively. The concentration of activation reagent solution was $10 \%$. The impregnation ratio was 1:1. Then, the TKMS was filtered from the mixed solution and subjected to pyrolysis for conversion into Trichosanthes kirilowii Maxim shell activated carbon (TKMC) in tube furnace. As for activation step, the TKMS was conducted for 45 min at different carbonization temperatures $(873 \mathrm{~K}, 923 \mathrm{~K}$ and $973 \mathrm{~K})$ under a continuous $\mathrm{N}_{2}$ flow of $0.30 \mathrm{~L} / \mathrm{min}$. Finally, the TKMC obtained was washed to neutral by using distilled water and dried at $333 \mathrm{~K}$.

Methylene blue was chosen as the adsorbate in this study. In order to prepare the stock solution of methylene blue, methylene blue (1 g) was dissolved in distilled water $(1000 \mathrm{~mL})$. Other chemicals were obtained from Aladdin Industrial Corporation (Shanghai, China)

In order to make it easy to distinguish the different types of TKMC, the following nomenclature was used:

$\mathrm{TKMC}_{\mathrm{N}}$ : TKMS soaked by distilled water

$\mathrm{TKMC}_{\mathrm{Zn}}$ : TKMS soaked by $\mathrm{ZnCl}_{2}$ solution

$\mathrm{TKMC}_{\mathrm{Na}}$ : TKMS soaked by $\mathrm{NaOH}$ solution

$\mathrm{TKMC}_{\mathrm{K}}$ : TKMS soaked by $\mathrm{KOH}$ solution

\section{Method}

The stock solution of methylene blue was diluted at various levels to afford initial adsorbate solutions of preset concentrations. The adsorption experiments 
were carried out at $303 \mathrm{~K}, 313 \mathrm{~K}$, and $323 \mathrm{~K}$ with the initial adsorbate concentration ranging from $250 \mathrm{mg} / \mathrm{L}$ to $400 \mathrm{mg} / \mathrm{L}$ to evaluate the temperature effect on TKMC's adsorption capacity toward methylene blue. Next, time effect during the adsorption process was assessed by mixing $300 \mathrm{~mL}$ of $300 \mathrm{mg} / \mathrm{L}$ methylene blue solution with $150 \mathrm{mg}$ of TKMC. Other runs of adsorption were begun with mixing $10 \mathrm{mg}$ of TKMC and $20 \mathrm{~mL}$ of adsorbate solutions after adsorption experiments was measured via UV spectrophotometer (TU-1810, Beijing general instrument co. LTD). The amount of methylene blue adsorbed could be calculated using the equation below:

$q_{e}=\left(c_{i}-c_{3}\right) V / M$

where $q_{e}$ is the adsorption amount $(\mathrm{mg} / \mathrm{g})$ based on the initial weight of methylene blue, while $c_{i}$ and $c_{e}$ are the methylene blue concentrations at the beginning and after reaching equilibrium, respectively.

Pore characteristics of TKMC were analyzed by nitrogen adsorption at 77K (Micromeritics ASAP 2460). Brunauer-Emmett-Teller (BET) equation was employed for surface area calculation. Nitrogen adsorption volume at the relative pressure 0.95 was converted into adsorbate's equivalent liquid volume to calculate the total pore volume (VT), while t-plot approach was adopted for the acquirement of micropore or external surface, as well as the micropore volume. Moreover, surface morphology and chemical composition of the materials were characterized by scanning electron microscopy(SEM, Evo18 Carl Zeiss AG, Germany) and Fourier transform infrared (FTIR,Nicolet iS50, Thermo Scientific, USA) spectroscopy, respectively.

\section{RESULTS AND DISCUSSION}

\section{Selection of the activation agent}

It is known that how well an activated carbon absorbent can work relies heavily on the selection of activation agent ${ }^{18}$. Fig. 1 collects the adsorption capacity values for all types of TKMCs. Compared to the adsorption capacity of $\mathrm{TKMC}_{\mathrm{N}}(86.80 \mathrm{mg} / \mathrm{g})$, values of $\mathrm{TKMC}_{\mathrm{Zn}}$ (190.56 mg/g), TKMC ${ }_{\mathrm{Na}}(225.60 \mathrm{mg} / \mathrm{g})$ and $\mathrm{TKMC}_{\mathrm{K}}$ $(544.16 \mathrm{mg} / \mathrm{g})$ were enhanced by $120 \%, 160 \%$ and $530 \%$, respectively. Zinc chloride will inhibit the formation of tar and promote pyrogenation during pyrolysis process. The microporous structure was formed due to aroma-

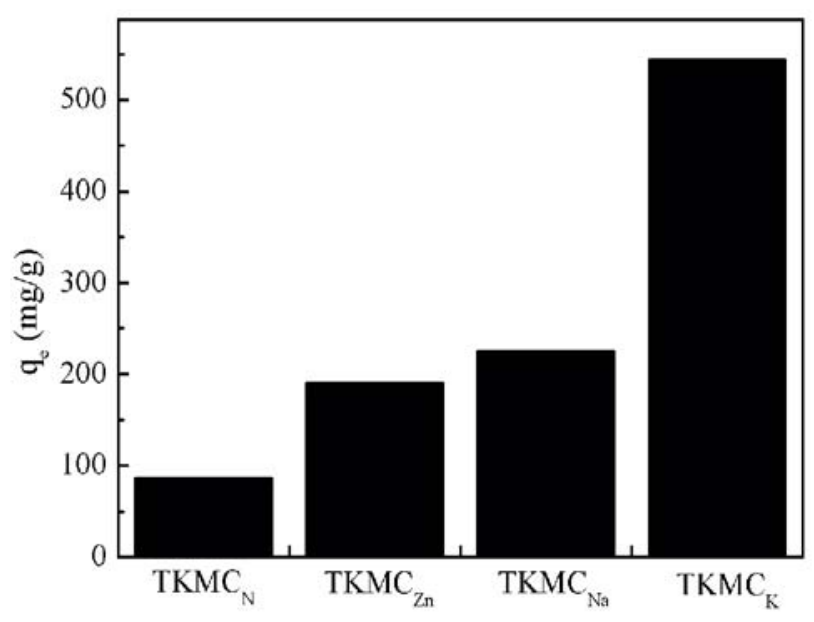

Figure 1. Effect of activation temperature tization during carbonization. According to the basicity strength of alkali metal hydroxides, $\mathrm{KOH}$ is more alkaline than $\mathrm{NaOH}$ when dissolved in water due to the lower ionisation energy of potassium $(\mathrm{K})$ atom compared to sodium $(\mathrm{Na})$ atom. The better activation performance of $\mathrm{KOH}$ is attributed to the metallic potassium reduced from the basic cation form, for it could be individually inserted into the carbon walls to separate and degrade the graphitic layers, thereby affording numerous micropores and mesopores ${ }^{19}$. Hence, the following experiments were established on the basis of $\mathrm{KOH}$ activation.

Fig. 2 presents the adsorption uptake capacity of methylene blue on $\mathrm{TKMC}_{\mathrm{K}}$ at different carbonization temperatures $(873 \mathrm{~K}, 923 \mathrm{~K}$ and $973 \mathrm{~K})$. Increasing amount of methylene blue adsorption was observed at higher carbonization temperature. Therefore, $973 \mathrm{~K}$ was selected as the optimum carbonization temperature. After carbonization, $\mathrm{S}_{\mathrm{BET},} \mathrm{S}_{\text {mic, }} \mathrm{S}_{\text {ext, }} \mathrm{S}_{\text {lang, }} \mathrm{V}_{\text {total, }} \mathrm{V}_{\text {mic, }} \mathrm{V}_{\text {mes }}$ and $\mathrm{D}_{\text {ave }}$ all increased accordingly as listed in Table1. $\mathrm{S}_{\mathrm{BET}}, \mathrm{S}_{\text {mic, }}$ $\mathrm{S}_{\text {ext, }} \mathrm{S}_{\text {lang, }} \mathrm{V}_{\text {total, }} \mathrm{V}_{\text {mic, }} \mathrm{V}_{\text {mes }}$ and $\mathrm{D}_{\text {ave }}$ increase from 315.31 to $657.78 \mathrm{~m}^{2} / \mathrm{g}, 273.97$ to $284.79 \mathrm{~m}^{2} / \mathrm{g}, 41.33$ to 372.98 $\mathrm{m}^{2} / \mathrm{g}, 439.88$ to $922.34 \mathrm{~m}^{2} / \mathrm{g}, 0.18$ to $0.45 \mathrm{~cm}^{3} / \mathrm{g}, 0.13$ to $0.14 \mathrm{~cm}^{3} / \mathrm{g}, 0.04$ to $0.30 \mathrm{~cm}^{3} / \mathrm{g}$, and 62.28 to $65.22 \AA$, respectively. As known, porous characteristic parameters would change significantly during the activation process and pyrolysis process. Fig. 3 further gives the nitrogen adsorption/desorption isotherms of $\mathrm{TKMC}_{\mathrm{N}}$ and $\mathrm{TKMC}_{\mathrm{K}}$.

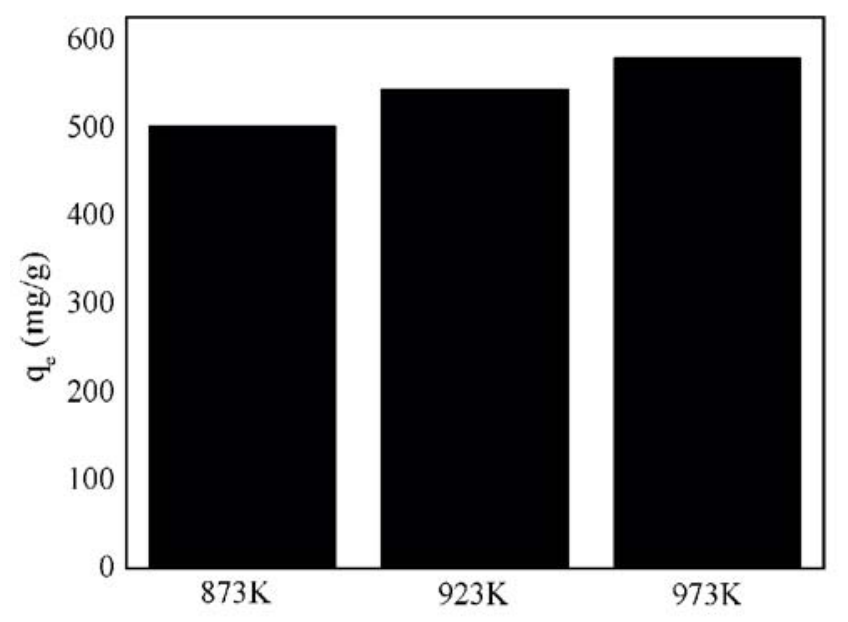

Figure 2. Effect of carbonization temperature

Table 1. Porosity structures of the $\mathrm{TKMC}_{\mathrm{N}}$ and $\mathrm{TKMC}_{\mathrm{K}}$

\begin{tabular}{|l|r|r|}
\hline & TKMC $_{\mathrm{N}}$ & TKMC $_{\mathrm{K}}$ \\
\hline $\mathrm{S}_{\mathrm{BET}}$-BET surface area $\left(\mathrm{m}^{2} / \mathrm{g}\right)$ & 315.31 & 657.78 \\
\hline $\mathrm{S}_{\text {mic }}-$ Micropore surface area $\left(\mathrm{m}^{2} / \mathrm{g}\right)$ & 273.97 & 284.79 \\
\hline $\mathrm{S}_{\text {ext }}-$ External surface area $\left(\mathrm{m}^{2} / \mathrm{g}\right)$ & 41.33 & 372.98 \\
\hline $\mathrm{S}_{\text {lan }}$-Langmuir surface area $\left(\mathrm{m}^{2} / \mathrm{g}\right)$ & 439.88 & 922.34 \\
\hline $\mathrm{V}_{\text {total }}$-Total pore volume $\left(\mathrm{cm}^{3} / \mathrm{g}\right)$ & 0.18 & 0.45 \\
\hline $\mathrm{V}_{\text {mic }}-$ Micropore volume $\left(\mathrm{cm}^{3} / \mathrm{g}\right)$ & 0.13 & 0.14 \\
\hline $\mathrm{V}_{\text {mes }}-$ Mesopore volume $\left(\mathrm{cm}^{3} / \mathrm{g}\right)$ & 0.04 & 0.31 \\
\hline $\mathrm{D}_{\text {ave }}$-Average pore size $(\AA)$ & 62.28 & 65.22 \\
\hline
\end{tabular}

\section{Characterization of char and activated carbon}

Fig. 4 presents the SEM images of $\mathrm{TKMC}_{\mathrm{N}}$ and $\mathrm{TKMC}_{\mathrm{K}}$ at $5000 \mathrm{X}$ and $15000 \mathrm{X}$ magnifications to reveal intuitively their physical morphologies on the surface. As clearly shown, $\mathrm{TKMC}_{\mathrm{N}}$ possessed a compact and smooth surface (Fig.4 a-b), while by contrast, the surface of $\mathrm{TKMC}_{\mathrm{K}}$ was markedly porous and widely distributed with all sorts of irregular cavities (Fig. 4c-d). These cavities were 


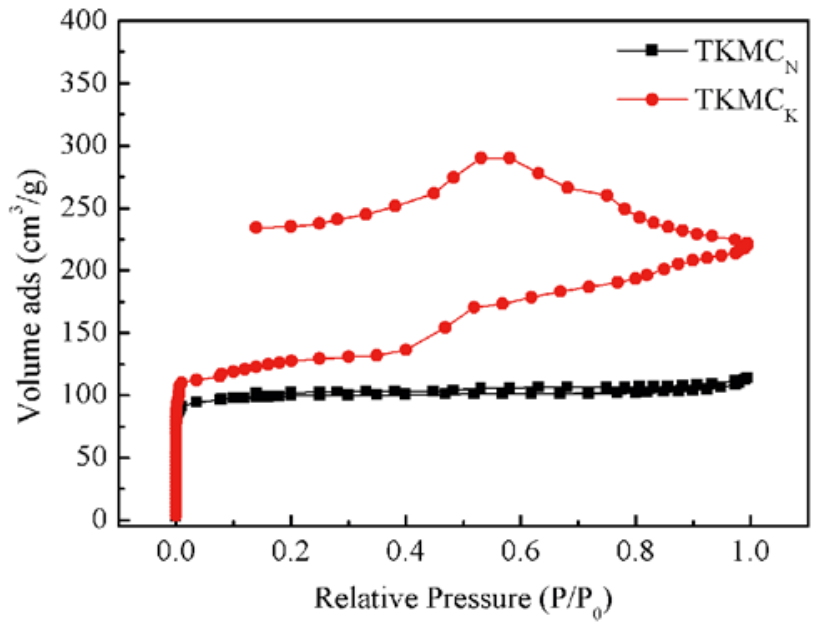

Figure 3. Nitrogen adsorption/desorption isotherms of $\mathrm{TKMC}_{\mathrm{N}}$ and $\mathrm{TKMC}_{\mathrm{K}}$
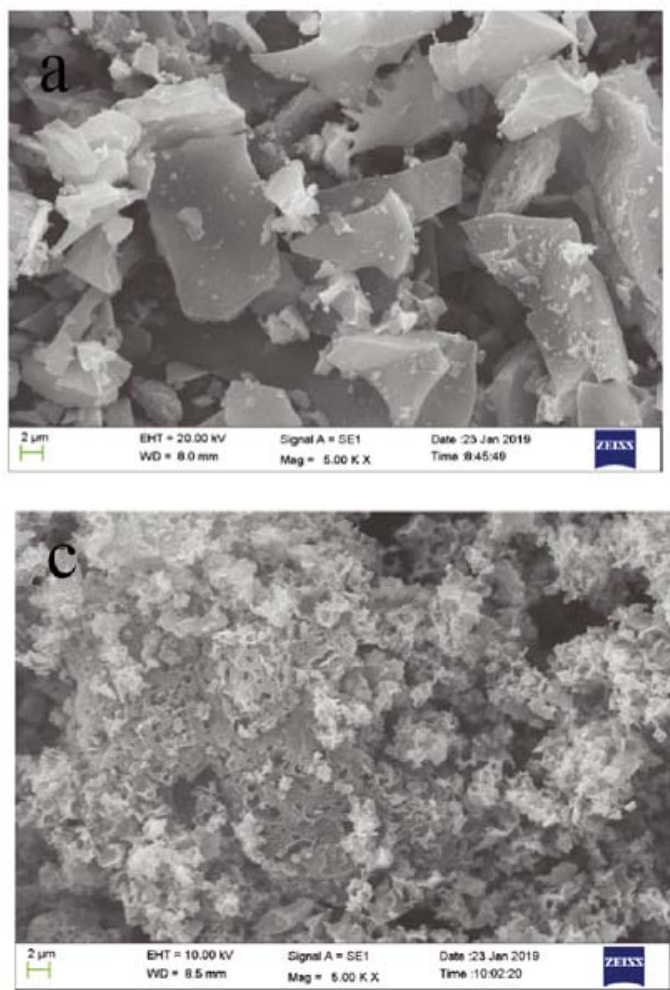

Figure 4. SEM images of $\mathrm{TKMC}_{\mathrm{N}}$ and $\mathrm{TKMC}_{\mathrm{K}}$

attributed to the space which was left by the removal of compound derived from $\mathrm{KOH}$ and embedded formerly in the reagent system.

FTIR spectra of $\mathrm{TKMC}_{\mathrm{N}}$ and $\mathrm{TKMC}_{\mathrm{K}}$ are recorded in Fig. 5. The transmittance bands at $1425.00 \mathrm{~cm}^{-1}, 1557.29$ $\mathrm{cm}^{-1}$ and $1030.51 \mathrm{~cm}^{-1}$ are associated with $\mathrm{CH}_{2}$ on alkyl groups $^{20}, \mathrm{O}-\mathrm{H}$ on hydroxyl groups ${ }^{21}$, and $\mathrm{C}-\mathrm{O}-\mathrm{C}$ on anhydrides groups ${ }^{22}$, respectively. Additionally, the band at $1425.10 \mathrm{~cm}^{-1}$ newly appeared after the activation process, while the band at $1557.29 \mathrm{~cm}^{-1}$ almost disappeared due to the effect of $\mathrm{KOH}$.

\section{Regulation of the adsorbent dosage}

Since the adsorption capacity at a certain initial concentration of adsorbate is much dependent on the dose of adsorbent, adsorption behavior towards methylene blue was assessed at different $\mathrm{TKMC}_{\mathrm{K}}$ dose. As shown in Fig. 6, higher percentage of adsorbate removal was achieved at larger dosage at $\mathrm{TKMC}_{\mathrm{K}}$, whereas the

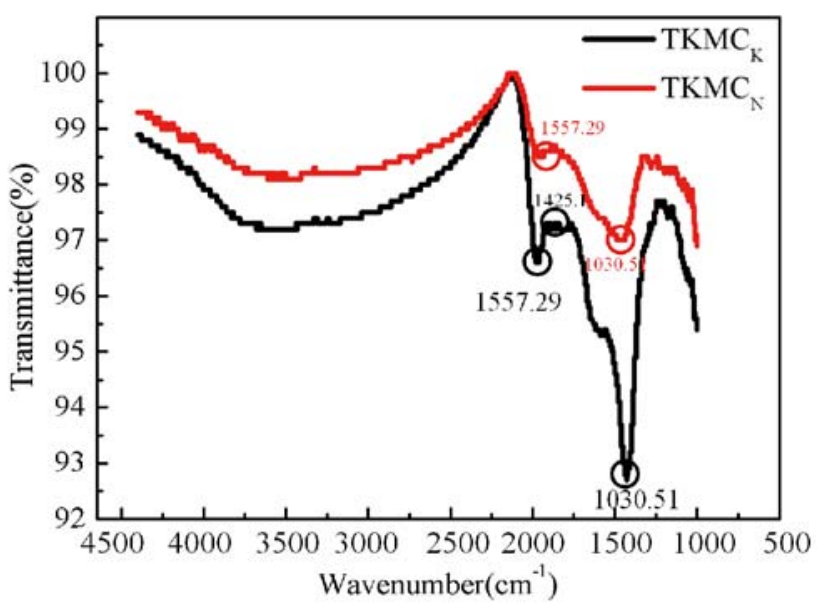

Figure 5. FTIR spectra of $\mathrm{TKMC}_{\mathrm{N}}$ and $\mathrm{TKMC}_{\mathrm{K}}$
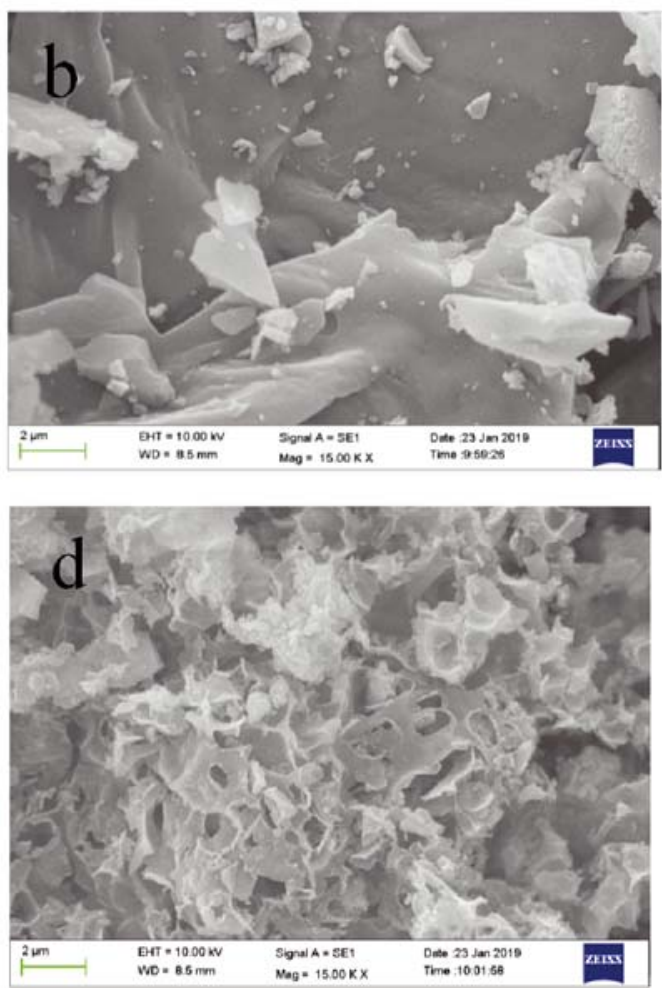

amount of methylene blue adsorbed by the adsorbent per unit mass had decreased. Such decline in the unit

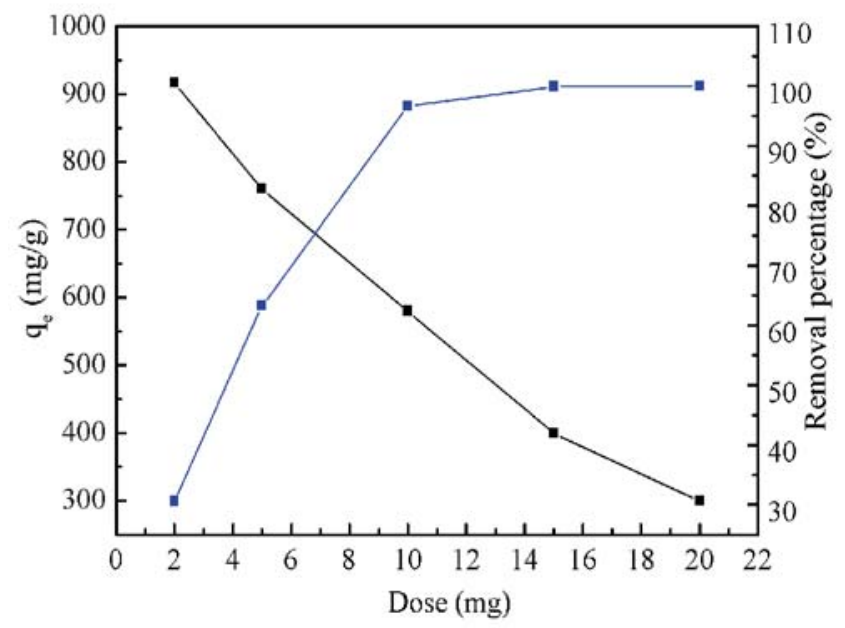

Figure 6. Effect of adsorbent dosage 
adsorption at mounting $\mathrm{TKMC}_{\mathrm{K}}$ dosage might result from the unsaturation of adsorption sites in the process of adsorption ${ }^{23}$.

\section{pH effect}

Solution $\mathrm{pH}$ of the adsorption system plays a significant role during the adsorption process ${ }^{24}$. Fig. 7 depicts the $\mathrm{TKMC}_{\mathrm{K}}$ adsorption behavior towards methylene blue under different $\mathrm{pH}$ conditions. As can be seen, more dye molecules could be removed at higher $\mathrm{pH}$ values, where the removal percentage was enhanced from $92.12 \%$ to $99.52 \%$ as the $\mathrm{pH}$ increased from 3 to 10 . Moreover, the effect of $\mathrm{pH}$ value was especially significant over the range of $3 \sim 7$, while the adsorption improvement approached to steadiness at $\mathrm{pH}$ higher than 7 .

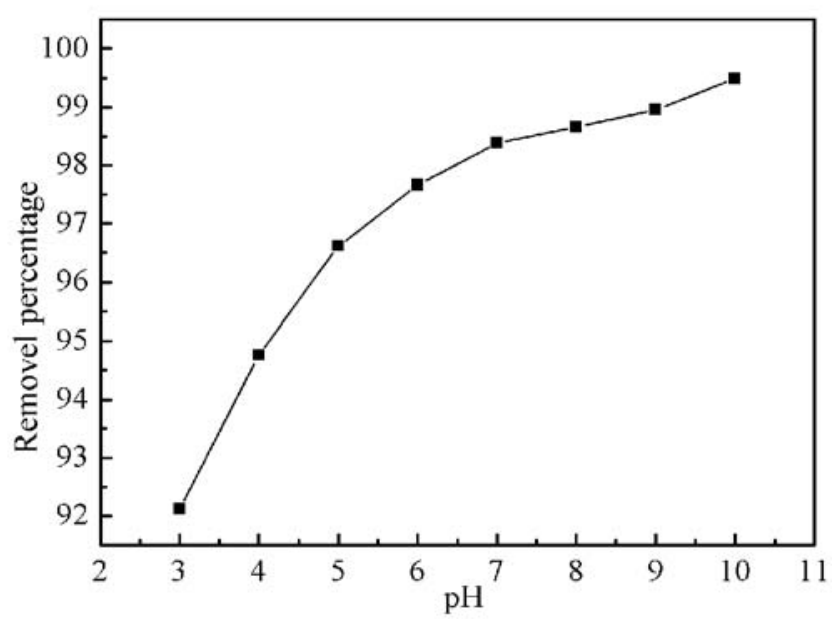

Figure 7. Effect of $\mathrm{pH}$

The underlying mechanism accounting for the interaction between $\mathrm{TKMC}_{\mathrm{K}}$ and dye molecules under varied $\mathrm{pH}$ conditions was further explored ${ }^{\mathbf{1 6}}$, as shown in Fig. 8 (a)-(c). At pH around 7, an interaction could

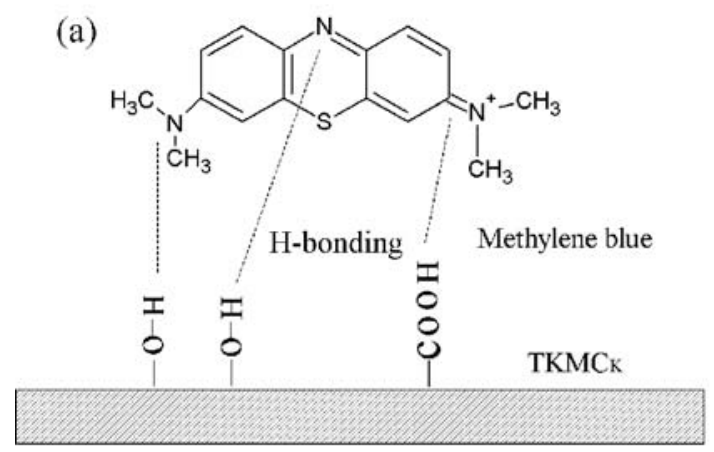

be well established between the hydroxyl and carboxyl groups on the adsorbent surface and the nitrogen atoms exiting in the adsorbate molecules. As the $\mathrm{pH}$ value increased, those oxygen-containing functional groups from the adsorbent would be further deprotonated into the ones carrying negative charges, which conduced to an enhanced electrostatic attraction with the dye molecules holding positive charges in the form of hydrogen bonding. However,-OH and -COOH groups on $\mathrm{TKMC}_{\mathrm{K}}$ surface would be protonated in acidic solutions, and resultant positive charges in excess amount could incur an intense electrostatic repulsion between the adsorbent and adsorbate, thereby reducing the adsorption efficiency ${ }^{25}$. In short, alkaline environment could much favor $\mathrm{TKMC}_{\mathrm{K}}$ adsorption behavior toward methylene blue molecules.

\section{Effect of adsorption time}

The variation of adsorption capacity $\left(q_{t}, \mathrm{mg} / \mathrm{g}\right)$ along with the extension of adsorption time was recorded at $303 \mathrm{~K}$, as shown in Fig. 9. Apparently, $\mathrm{q}_{\mathrm{t}}$ increased as

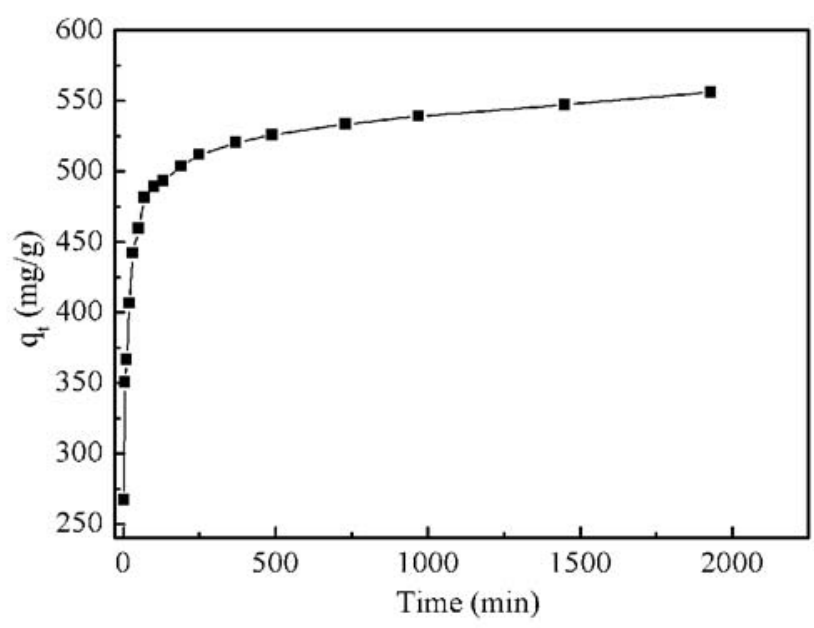

Figure 9. Effect of adsorption time

(b)

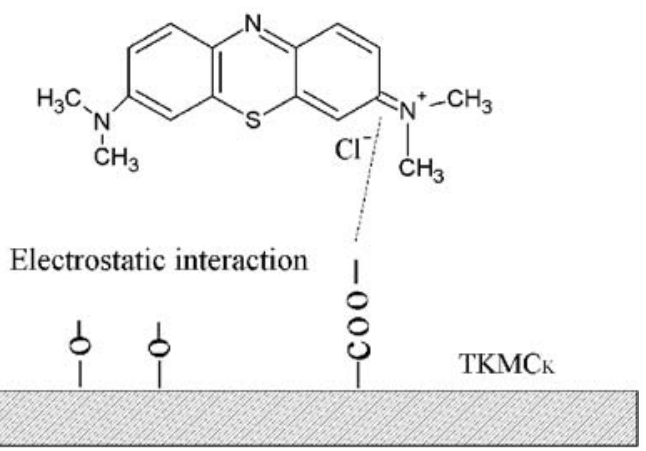

(c)<smiles>CN(C)c1ccc2nc3ccc(=[N+](C)C)cc-3sc2c1</smiles>

Electrostatic repulsion

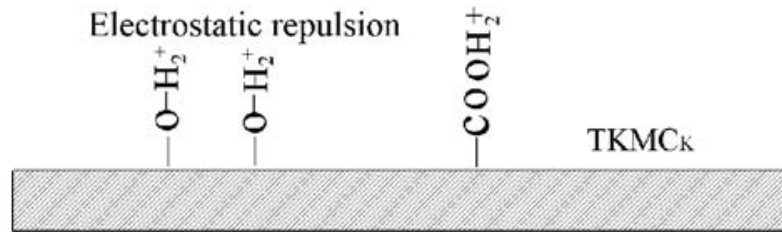

Figure 8. $\mathrm{TKMC}_{\mathrm{K}}$-methylene blue interaction under different $\mathrm{pH}$ conditions: (a)neutral, (b)alkaline, and (c)acidic 
time went on, and the uptake of methylene blue rose rapidly in the first $100 \mathrm{~min}$. Afterwards, the growth rate tapered down till no more changed when the adsorbents were saturated.

\section{Effect of initial adsorbate concentration}

The adsorption capacity of $\mathrm{TKMC}_{\mathrm{K}}$ towards methylene blue was measured when setting the initial adsorbate concentration at different values. Results in Fig. 10 suggested an obvious concentration effect on methylene blue removal, where a higher initial concentration of the adsorbate led to a greater driving force of the mass transfer and thus an enhanced loading capacity of the adsorbent. Specifically, at $323 \mathrm{~K}, \mathrm{TKMC}_{\mathrm{K}}$ had a loading capacity of $785.78 \mathrm{mg}$ adsorbate/g adsorbate at an initial adsorbate concentration of $400 \mathrm{mg} / \mathrm{L}$, which was improved a lot from the value of $500 \mathrm{mg}$ adsorbate/g adsorbate at initial adsorbate concentration of $250 \mathrm{mg} / \mathrm{L}$.

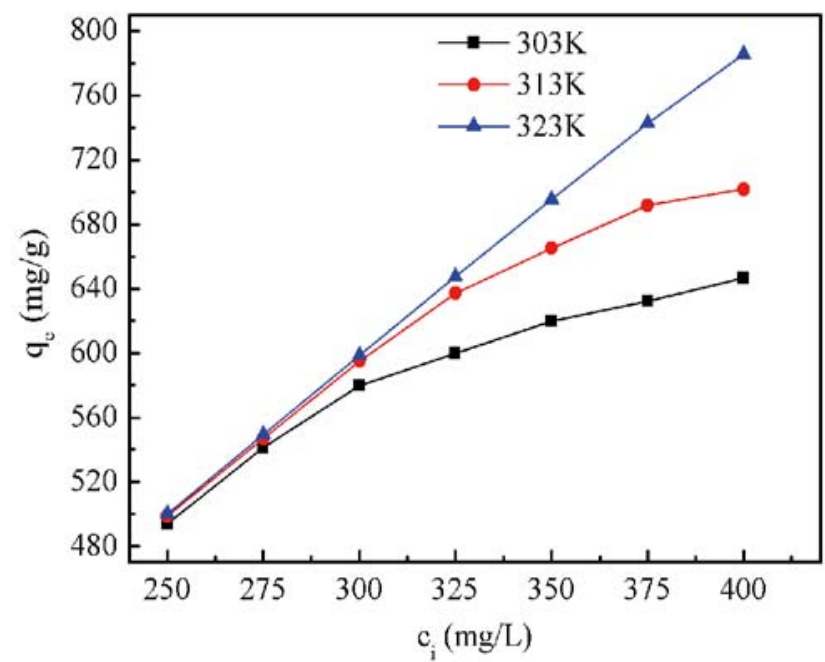

Figure 10. Effect of initial dye concentration

\section{Influence of the adsorption temperature}

Adsorption experiments were conducted at $303 \mathrm{~K}$, $313 \mathrm{~K}$, and $323 \mathrm{~K}$, successively, and the adsorption behavior of $\mathrm{TKMC}_{\mathrm{K}}$ toward methylene blue was found to be progressively improved (Fig. 11). According to the adsorption date listed in Table 2, a temperature increase from $303 \mathrm{~K}$ to $323 \mathrm{~K}$ could bring an increase from 649.35 to $793.65 \mathrm{mg} / \mathrm{g}$ in the adsorption capacity of $\mathrm{TKMC}_{\mathrm{K}}$. Hence, the adsorption process in this work was determined as an endothermic one.

\section{Isotherm studies}

Delicate design and subsequent optimization depend on the accurate plotting of equilibrium adsorption isotherms, for they can reveal in-depth the exact interaction between adsorbents and adsorbates ${ }^{25}$.The adsorption date obtained in this work were tentatively fit with both Langmuir adsorption isotherm and Freundlich adsorption isotherm by using the equations listed below ${ }^{\mathbf{2 6}}$ :

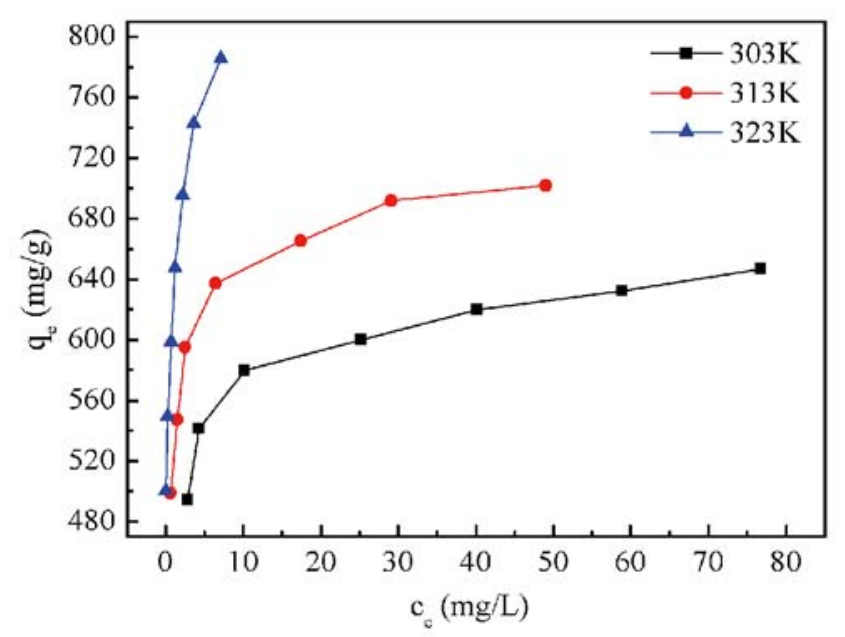

Figure 11. Effect of adsorption temperature

$c_{e} / q_{\mathrm{e}}=\frac{1}{b q_{m}}+c_{e} / q_{m}$

$R_{L}=1 /\left(1+b c_{i}\right)$

$\ln q_{\mathrm{e}}=\ln k_{F}+(1 / n) \ln c_{e}$

where $b$ and $k_{F}$ are the Langmuir constant and the Freundlich constant, respectively, $q_{m}$-refers to the adsorption capacity at full coverage of adsorbate on the adsorbent surface, and $R_{L}$ is a dimensionless constant separation factor that determines whether the adsorption isotherm is in a favorable shape. Specifically, the adsorption process is an unfavorable one at $R_{L}>1.0$, a favorable one at $1>R_{L}>0$ (the case of $R_{L}=1.0$ follows a linear trend), and an irreversible one at $R_{L}=1.0$.

The straight line of $c_{e} / q_{e}$ versus $c_{e}$ could afford $q_{m}$ as the slope and $b$ as the intercept (Fig. 12), while the linear plot of $\ln q_{e}$ against $h c_{e}$ could deduce $k_{F}$ and 1/n (Fig. 13).

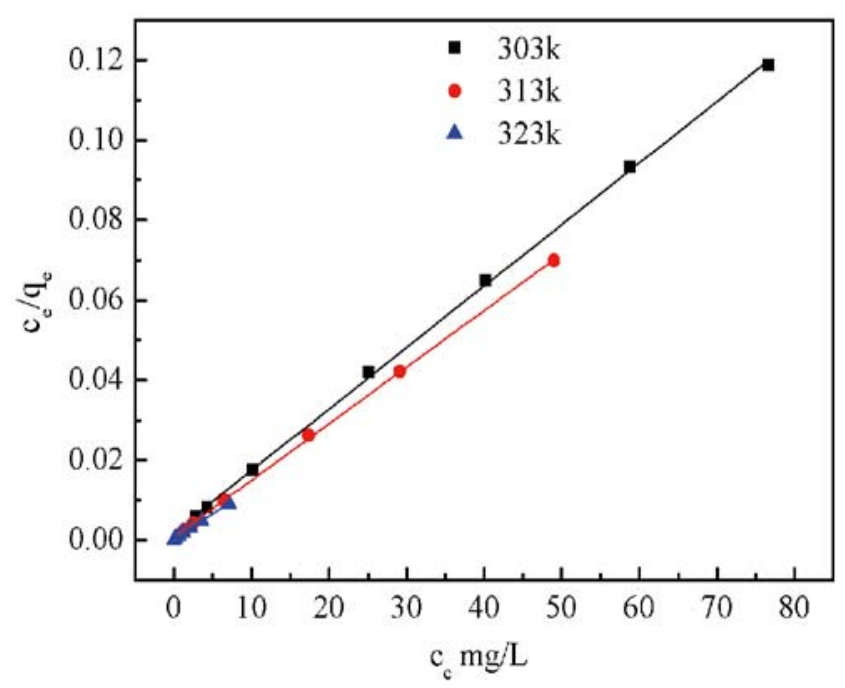

Figure 12. Langmuir adsorption isotherm

Table 2. The calculation parameters of Adsorption equilibrium isotherm models

\begin{tabular}{|l|c|c|c|c|c|c|c|}
\hline $\mathrm{T} / \mathrm{K}$ & \multicolumn{3}{|c|}{ Langmuir } & \multicolumn{3}{c|}{ Freundlich } \\
\hline & $q_{\mathrm{m}}[\mathrm{mg} / \mathrm{g}]$ & $\mathrm{B}[\mathrm{L} / \mathrm{mg}]$ & $R^{2}$ & $R_{\mathrm{L}}$ & $k_{\mathrm{F}}[\mathrm{L} / \mathrm{mg}]$ & $1 / \mathrm{n}$ & $R^{2}$ \\
\hline 303 & 649.35 & 0.74 & 0.99 & 0.0053 & 475.14 & 0.07 & 0.93 \\
\hline 313 & 704.23 & 1.82 & 0.99 & 0.0022 & 535.41 & 0.07 & 0.94 \\
\hline 323 & 793.65 & 5.55 & 0.99 & 0.0007 & 635.57 & 0.11 & 0.99 \\
\hline
\end{tabular}




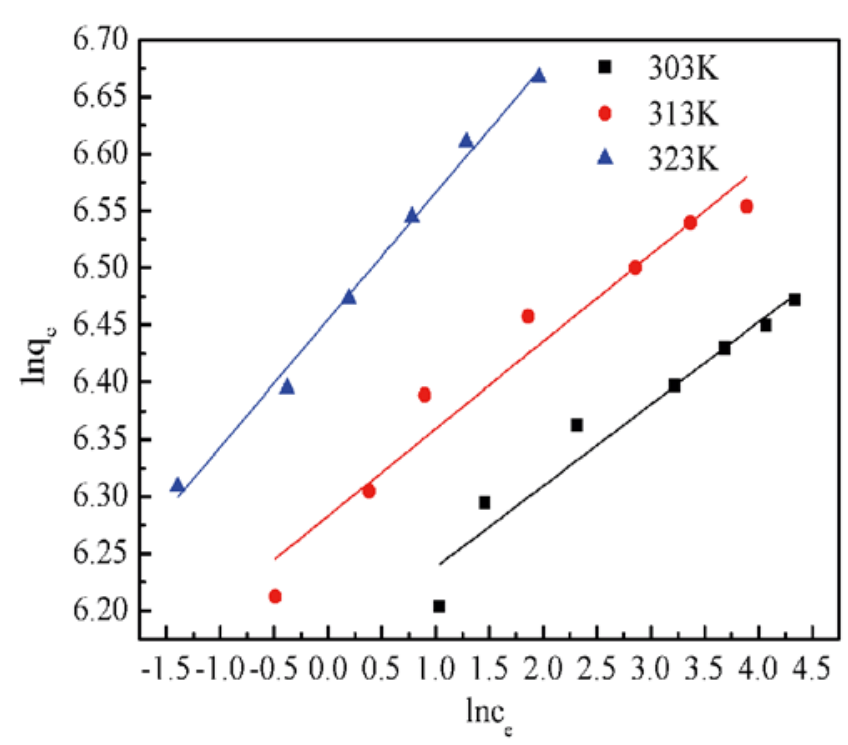

Figure 13. Freundlich adsorption isotherm

Adsorption isotherms were determined from experimental adsorption results through Langmuir equation (2) and Freundlich equation (4), and the values of parameters $q_{m}, b, k_{F}, R_{L}$ and $1 / \mathrm{n}$ are gathered in Table 2 . The least square method was used for calculating the isotherm data, which gave a higher $\mathrm{R}^{2}$ value (related correlation coefficient) for the Langmuir model than for the Freundlich model. Therefore, the results showed a better agreement between the Langmuir equation and adsorption data, implying that the active adsorption sites were homogeneously distributed throughout the surface of $\mathrm{TKMC}_{\mathrm{K}}$ given the assumption of homogeneous adsorption in the Langmuir model. According to the isotherms, $\mathrm{TKMC}_{\mathrm{K}}$ per kilogram could adsorb up to $649.35 \mathrm{mg}$ of methylene blue at $303 \mathrm{~K}, 704.23 \mathrm{mg}$ at $313 \mathrm{~K}$, and $793.65 \mathrm{mg}$ at $323 \mathrm{~K}$. Apparently, greater adsorption capacity of $\mathrm{TKMC}_{\mathrm{K}}$ could be achieved at higher adsorption temperature. Adsorption capacities of other biomass activated carbon materials toward methylene blue are further compared in Table 3, including bamboo-based $\mathrm{AC}^{27}$, paper waste-based $\mathrm{AC}^{28}$, walnut cake $\mathrm{AC}^{29}$, optimized waste tea $\mathrm{AC}^{30}$, dead leaves $\mathrm{AC}^{31}$, and vetiver roots $\mathrm{AC}^{32}$.

\section{Adsorption kinetics}

Three kinetic models, namely the pseudo-first-order model ${ }^{33}$, the pseudo-second-order model ${ }^{25}$, and the intraparticle diffusion model $^{34}$, were employed to investigate the kinetic process of $\mathrm{TKMC}_{\mathrm{K}}$ adsorbing methylene blue. The following equations were used for describing these kinetic models:

$\log \left(q_{e}-q_{t}\right)=\log q_{e}-\frac{k_{p f}}{2.303} t$ $\frac{t}{q_{t}}=\frac{t}{q_{e}}+\frac{1}{k_{p s} q_{e}^{2}}$

$q_{t}=k_{i d} t^{12}+C$

where $t$ is the adsorption duration, $q_{t}$ represents the adsorption quantity at certain, $\mathrm{t}, k_{p f}$ and $k_{p s}$ are the rate constants of the pseudo-first-order and the pseudo-second order kinetic models, respectively, while $k_{i d}$ stands for that of the intraparticle diffusion kinetic model.

Table 4 collects the calculation results for $q_{e}, k_{p f}, k_{p s}, k_{i d}$ and $C$ along with the corresponding $R^{2}$ values from linear regression. Equation (5) implies that each $\log \left(q_{e}-q_{t}\right)-t$ plot could generate one linear graph with the slope of

Table 4. The calculation parameters of adsorption kinetics models

\begin{tabular}{|l|c|c|}
\hline Kinetic model & Parameters & Values \\
\hline \multirow{4}{*}{ Pseudo-first-order } & $p f\left[\mathrm{~min}^{-1}\right]$ & $8.21 \times 10^{-4}$ \\
\cline { 2 - 3 } & $q_{\mathrm{e}}[\mathrm{mg} / \mathrm{g}]$ & 137.54 \\
\cline { 2 - 3 } & $R^{2}$ & 0.59 \\
\hline \multirow{3}{*}{$\begin{array}{l}\text { Pseudo-second- } \\
\text { order }\end{array}$} & $p^{2}$ & $1.35 \times 10^{-4}$ \\
\cline { 2 - 3 } & $q_{\mathrm{e}}$ & 552.49 \\
\cline { 2 - 3 } & $R^{2}$ & 0.99 \\
\cline { 2 - 3 } $\begin{array}{l}\text { Intraparticle } \\
\text { diffusion model }\end{array}$ & $\underline{k}_{\text {id } 1}$ & 27.76 \\
\cline { 2 - 3 } & $c_{1}$ & 268.49 \\
\cline { 2 - 3 } & $R_{1}{ }^{2}$ & 0.88 \\
\cline { 2 - 3 } & $k_{\text {id2 }}$ & 1.91 \\
\cline { 2 - 3 } & $c_{2}$ & 477.59 \\
\hline
\end{tabular}

$k_{p f}$

$-\overline{2.303}$, and $q_{e}$ could be calculated from the intercept on the y-axis as shown in Fig. 14(a). Equation (7) implies that each $q_{t}-t^{1 / 2}$ plot could generate one linear graph with the slope as $k_{i d}$, and $c_{i}$ could be calculated from the intercept on the y-axis as shown in Fig. 14(c). Equation (6) implies that each $\frac{t}{q_{t}}-t$ plot could generate one linear $\frac{1}{q_{e}}$

graph with the slope of $q_{e}$, and $k_{p s}$ could be calculated from the intercept on the y-axis as shown in Fig. 14(b). The correlation coefficient is 0.99 . Compared with the correlation coefficient of equation (5) and equation (7), the correlation coefficient of equation (6) is higher. Therefore, methylene blue adsorption to $\mathrm{TKMC}_{\mathrm{K}}$ conforms more to the pseudo-second-order kinetic model.

\section{Estimation of thermodynamic parameters}

The spontaneous nature and the thermodynamic feasibility can be described by thermodynamic parameters, including $\Delta S$ (entropy change), $\Delta G$ (Gibbs free energy change), and $\Delta H$ (enthalpy change). They can be calculated by using Van't Hoff equation as shown below ${ }^{35}$.

\begin{tabular}{|c|c|c|c|c|c|c|}
\hline Dyes & Adsorbent & \multicolumn{4}{|c|}{ Experimental conditions } & Reference \\
\hline & & Dose $[\mathrm{g} / \mathrm{L}]$ & $\mathrm{pH}$ & Temp. [K] & $\mathrm{q}_{\max }[\mathrm{mg} / \mathrm{g}]$ & \\
\hline MB & $\mathrm{TKMC}_{\mathrm{K}}$ & 0.50 & 6.00 & 303 & 649.30 & This study \\
\hline MB & Bamboo based AC & 1.00 & 7.00 & 303 & 454.20 & 27 \\
\hline MB & Walnut cake AC & 0.10 & $\mathrm{~N} / \mathrm{A}$ & 303 & 243.04 & 29 \\
\hline $\mathrm{MB}$ & Vetiver roots $A C$ & 0.10 & $\mathrm{~N} / \mathrm{A}$ & 298 & 526.00 & 32 \\
\hline MB & Optimized waste tea AC & 1.10 & 2.00 & 323 & 554.30 & 30 \\
\hline MB & Dead leaves AC & 5.00 & 6.50 & 318 & 285.00 & 31 \\
\hline
\end{tabular}

Table 3. Adsorption capacity of methylene blue with different biomass activated carbon materials 

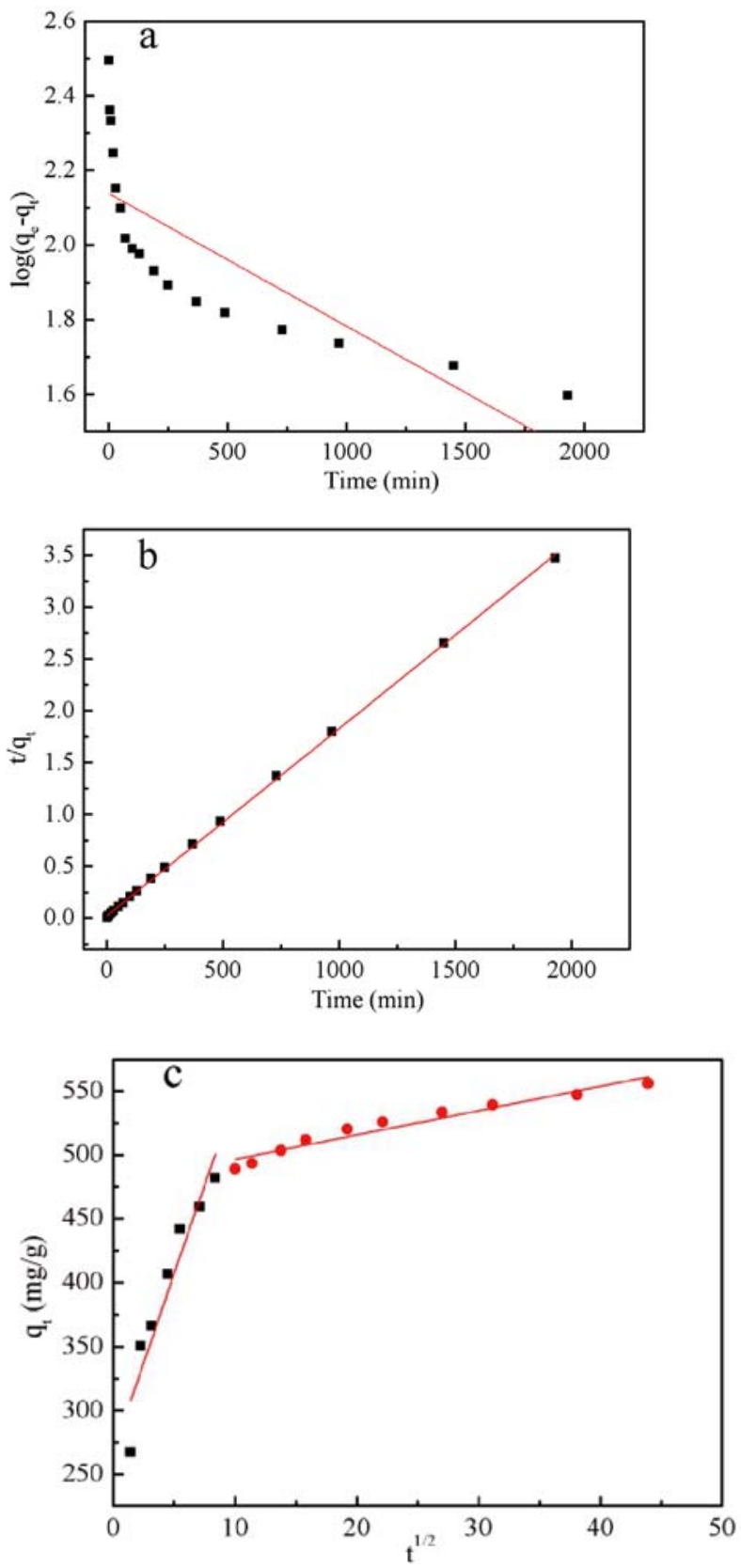

Figure 14. Kinetic model: (a) pseudo-first-order kinetic model (b) pseudo-second-order kinetic model (c) intraparticle diffusion kinetic model

$\ln \left(\frac{q_{e}}{c_{e}}\right)=-\frac{\Delta H}{R T}+\frac{\Delta S}{R}$

$\Delta G=\Delta H-T \Delta S$

where $R$ is the gas constant equal to $8.314 \mathrm{~J} /(\mathrm{mol} \mathrm{K})$, and $\mathrm{T}$ stands for temperature in Kelvin.

Then, slope and intercept of the linear $\ln \left(\frac{q_{e}}{c_{e}}\right)-1 / T$ plot were recorded individually as $\Delta S$ and $\Delta H$. All the parameters calculated from plots or equations are summarized in Table 5.

For the adsorption process in this work with $\mathrm{TKMC}_{\mathrm{K}}$ as the adsorbent and methylene blue as the adsorbate, $\Delta G$ was estimated as $-10207.17 \mathrm{~kJ} / \mathrm{mol}$ at $303 \mathrm{~K}$, $-14214.47 \mathrm{~kJ} / \mathrm{mol}$ at $313 \mathrm{~K}$, and $-118221.77 \mathrm{~kJ} / \mathrm{mol}$ at $323 \mathrm{~K}$, which indicated that methylene blue adsorption process to $\mathrm{TKMC}_{\mathrm{K}}$ is a spontaneous physisorption process. Meanwhile, $\Delta S$ and $\Delta H$ equaled $400.73 \mathrm{~J} / \mathrm{molK}$ and $111214.02 \mathrm{~kJ} / \mathrm{mol}$, respectively. The positive $\Delta H$ implied
Table 5. The values of thermodynamic parameters

\begin{tabular}{|l|c|c|c|}
\hline $\mathrm{T} / \mathrm{K}$ & $\triangle G[\mathrm{~kJ} / \mathrm{mol}]$ & $\triangle H[\mathrm{~kJ} / \mathrm{mol}]$ & $\triangle S[\mathrm{~J} / \mathrm{molK}]$ \\
\hline $303 \mathrm{~K}$ & -10207.17 & 111214.02 & 400.73 \\
\hline $313 \mathrm{~K}$ & -14214.47 & & \\
\hline $323 \mathrm{~K}$ & -118221.77 & & \\
\hline
\end{tabular}

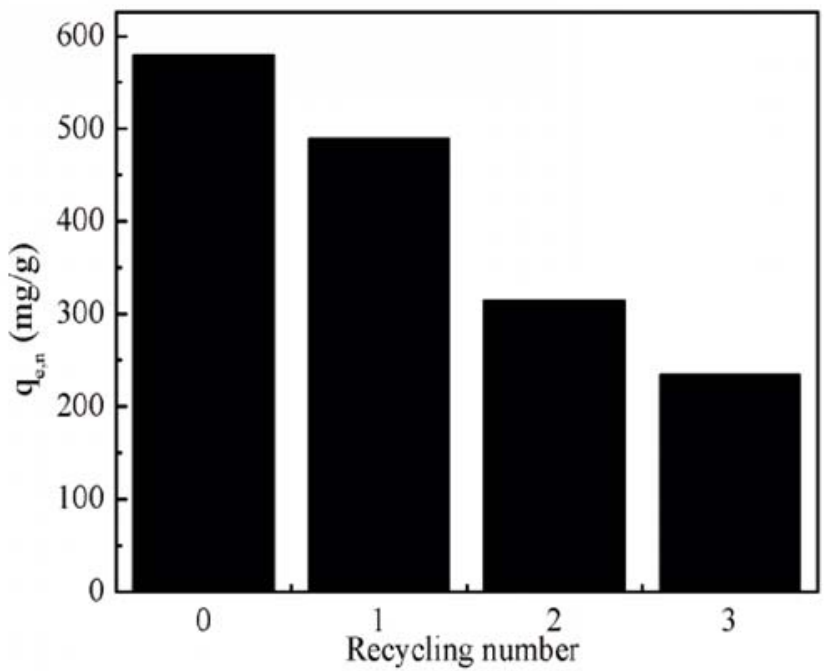

Figure 15. Effect of recycling number

an endothermal feature of the adsorption process, while the positive $\Delta S$ hinted that $\mathrm{TKMC}_{\mathrm{K}}$ was attractive towards methylene blue.

\section{Desorption studies}

To explore the reusability of $\mathrm{TKMC}_{\mathrm{K}}$, desorption experiment was performed at $0.001 \mathrm{M}$ hydrochloric acid. Fig. 15 shows the effect of recycling number on adsorption capacity of $\mathrm{TKMC}_{\mathrm{K}}$. The relative ratio of the adsorption capacity of each cycle was calculated by $\mathrm{q}_{\mathrm{e}, \mathrm{n}} / \mathrm{q}_{\mathrm{e}, 0}$, where $\mathrm{n}$ is the recycling number. The adsorption capacity of $\mathrm{TKMC}_{\mathrm{K}}$ decreased with the increase in recycling number. Three cycles of adsorption-desorption were completed with the relative ratio of adsorption capacity reaching up to $40 \%$.

\section{CONCLUSIONS}

In this study, the optimal activation condition was first developed to prepare $\mathrm{TKMC}_{\mathrm{K}}$ as the most desired adsorbent, where $\mathrm{KOH}$ was employed as the activation reagent, impregnation ratio was $1: 1$, and reaction temperature and time were $937 \mathrm{~K}$ and $45 \mathrm{~min}$, respectively. Influential factors for the adsorption capacity of $\mathrm{TKMC}_{\mathrm{K}}$ towards methylene blue included reagent type and temperature of the activation process, time, temperature, and $\mathrm{pH}$ condition of the adsorption process, as well as original dosage of the adsorbent and initial concentration of the adsorbate. $\mathrm{S}_{\mathrm{BET}}, \mathrm{S}_{\mathrm{mic}}, \mathrm{V}_{\text {total }}$ and $\mathrm{D}_{\text {ave }}$ values individually equal to $657.78 \mathrm{~m}^{2} / \mathrm{g}, 284.79 \mathrm{~m}^{2} / \mathrm{g}, 0.45 \mathrm{~cm}^{3} / \mathrm{g}$ and $65.22 \AA$ enabled $\mathrm{TKMC}_{\mathrm{K}}$ to well adsorb the methylene blue molecules. A better compliance with the Langmuir isotherm model indicated that the dye molecules were homogeneously adsorbed onto the $\mathrm{TKMC}_{\mathrm{K}}$ surface, while the kinetics studies suggested a pseudo-second-order feature for the adsorption process. Moreover, the spontaneity attribute, endothermic property, as well as thermodynamically favorable characteristics were revealed by both the enhanced adsorption capacity at higher adsorption 
temperature and thermodynamic parameters calculated. Therefore, the gratifying adsorption of $\mathrm{TKMC}_{\mathrm{K}}$ endows it with a promising prospect in the application field of agricultural adsorbents.

\section{ACKNOWLEDGMENTS}

This work was supported by the Qingdao Postdoctoral Science Foundation, National Natural Science Foundation of China (No. 51672140), Natural Science Foundation of Shandong Province (ZR2015EM038) and Taishan Scholar Program of Shandong Province (201511029).

\section{LITERATURE CITED}

1. Esmaeili, A. \& Khoshnevisan, N.(2016). Optimization of process parameters for removal of heavy metals by biomass of $\mathrm{Cu}$ and Co-doped alginate-coated chitosan nanoparticles. Bioresour. Technol., 218, 650-658. DOI: 10.1016/j.biortech.2016.07.005.

2. Khasri, A. \& Ahmad, M.A.(2018). Adsorption of basic and reactive dyes from aqueous solution onto Intsia bijuga sawdust-based activated carbon: batch and column study. Environ. Sci. Pollut. Res., 1-12. DOI: 10.1007/s11356-018-3046-3.

3. Aroguz, A.Z., Gulen, J. \& Evers, R.H.(2008). Adsorption of methylene blue from aqueous solution on pyrolyzed petrified sediment. Bioresour. Technol., 99, (6), 1503-1508. DOI: 10.1016/j.biortech.2007.04.033

4. Bruggen, B.V.D., Vandecasteele, C., Gestel, T.V., Doyen, W. \& Leysen, R.( 2010).A review of pressure - driven membrane processes in wastewater treatment and drinking water production. Environ. Prog. Sustainable Energy, 22, (1), 46-56. DOI: $10.1002 /$ ep.670220116.

5. Gogate, P.R. \& Pandit, A.B. (2004).A review of imperative technologies for wastewater treatment I: oxidation technologies at ambient conditions. Adv. Environ. Res.,8, (3), 501-551. DOI: 10.1016/S1093-0191(03)00032-7.

6. Li, Q., Li, Y.,Ma, X.,Du, Q.,Sui, K., Wang, D., Wang, C., Li, H. \& Xia, Y.(2017). Filtration and adsorption properties of porous calcium alginate membrane for methylene blue removal from water. Chem. Eng. J., 316, 623-630. DOI: 10.1016/j. cej.2017.01.098.

7. Bulut, Y. \& Aydın, H.(2006).A kinetics and thermodynamics study of methylene blue adsorption on wheat shells. Desalination, 194, (1), 259-267. DOI: 10.1016/j.desal.2005.10.032.

8. Chen, W., He, F., Zhang, S., Xv, H. \& Xv, Z.(2018).Development of porosity and surface chemistry of textile waste jute-based activated carbon by physical activation. Environ. Sci. Pollut. Res., 25, (10), 9840-9848. DOI: 10.1007/s11356018-1335-5.

9. Bello, O.S. \& Ahmad, M.A. (2011).Removal of Remazol Brilliant Violet-5R dye using periwinkle shells. Chem. Ecol., 27, (5), 481-492. DOI: 10.1080/02757540.2011.600696.

10. Karaçetin, G., Sivrikaya, S. \& Imamoğlu, M. (2014). Adsorption of methylene blue from aqueous solutions by activated carbon prepared from hazelnut husk using zinc chloride. J. Anal. Appl. Pyrolysis, 110, (1), 270-276. DOI: 10.1016/j. jaap.2014.09.006.

11. Mohammad, M., Maitra, S. \& Dutta, B.K.(2018). Comparison of activated carbon and physic seed hull for the removal of malachite green dye from aqueous solution. Water, Air, Soil Pollut., 229, (2), 45. DOI: 10.1007/s11270-018-3686-4.

12. Monteiro, M.S., De, R.F., Chaves, J., Santana, S.A., Silva, H. \& Bezerra, C. (2017). Wood (Bagassa guianensis Aubl) and green coconut mesocarp (cocos nucifera) residues as textile dye removers (Remazol Red and Remazol Brilliant Violet). J. Environ. Manage., 204, (Pt 1), 23-30. DOI: 10.1016/j. jenvman.2017.08.033.
13. García, J.R., Sedran, U., Zaini, M. A. \& Zakaria, Z. A.(2017).Preparation, characterization, and dye removal study of activated carbon prepared from palm kernel shell. Environ. Sci. Pollut. Res., 25, (1-3), 1-10. DOI: 10.1007/s11356-017-8975-8.

14. Spagnoli, A.A., Giannakoudakis, D.A. \& Bashkova, S. (2017). Adsorption of methylene blue on cashew nut Shell based carbons activated with zinc chloride: The role of surface and structural parameters. J. Mol. Liq., 229, 465-471. DOI: 10.1016/j.molliq.2016.12.106.

15. Khanday, W.A., Marrakchi, F., Asif, M. \& Hameed, B.H. (2016).Mesoporous zeolite-activated carbon composite from oil palm ash as an effective adsorbent for methylene blue. J. Taiwan Inst. Chem. Eng. 70:3-41. DOI: 10.1016/j.jtice.2016.10.029.

16. Khasri, A., Bello, O.S. \& Ahmad, M.A.(2018).Mesoporous activated carbon from Pentace species sawdust via microwave-induced $\mathrm{KOH}$ activation: optimization and methylene blue adsorption. Res. Chem. Intermed., 1-21. DOI: 10.1007/ s11164-018-3452-7.

17. Miyah, Y., Lahrichi, A., Idrissi, M., Khalil, A., Zerrouq, F. (2018). Adsorption of methylene blue dye from aqueous solutions onto walnut shells powder: equilibrium and kinetic studies. Surf. Interfaces, 11. 74-81. DOI: 10.1016/j.surfin.2018.03.006.

18. Malaika, A. \& Kozłowski, M.(2011).Modification of activated carbon with different agents and catalytic performance of products obtained in the process of ethylbenzene dehydrogenation coupled with nitrobenzene hydrogenation. Chem. Eng. J., 171, (3), 1348-1355. DOI: 10.1016/j.cej.2011.05.046.

19. Mckee, D.W. (1982).Gasification of graphite in carbon dioxide and water vapor-the catalytic effects of alkali metal salts. Carbon, 20, (1), 59-66. DOI: 10.1016/0008-6223(82)90075-6.

20. Foo, K.Y. \& Hameed, B.H. (2012).Coconut husk derived activated carbon via microwave induced activation: Effects of activation agents, preparation parameters and adsorption performance. Chem. Eng. J., 184, (2), 57-65. DOI: 10.1016/j. cej.2011.12.084.

21. Shen, F., Wang, Y., Li, L., Zhang, K., Smith, R.L. \& Qi, X.(2018).Porous carbonaceous materials from hydrothermal carbonization and $\mathrm{KOH}$ activation of corn stover for highly efficient $\mathrm{CO}_{2}$ capture. Chem. Eng. Commun., 205, (4), 423-431. DOI: $10.1080 / 00986445.2017 .1367671$.

22. Nikonenko, N.A., Buslov, D.K., Sushko, N.I. \& Zhbankov, R.G.(2015).Investigation of stretching vibrations of glycosidic linkages in disaccharides and polysaccharides with use of IR spectra,deconvolution.Biopolymers,57,(4),257-262.DOI: 10.1002/1097-0282(2000)57:4<257::AID-BIP7>3.0.CO;2-3

23. Kemer, B., Ozdes, D.,Gundogdu, A., Bulut, V.N., Duran, C. \& Soylak, M.(2009).Removal of fluoride ions from aqueous solution by waste mud. J. Hazard. Mater., 168, (2), 888-894. DOI: 10.1016/j.jhazmat.2009.02.109.

24. Wang, S., Boyjoo, Y. \& Choueib, A.(2005).A comparative study of dye removal using fly ash treated by different methods. Chemosphere, 60,(10), 1401-1407. DOI: 10.1016/j. chemosphere.2005.01.091.

25. Vadivelan, V. \& Kumar, K.V.(2005).Equilibrium, kinetics, mechanism, and process design for the sorption of methylene blue onto rice husk. J. Colloid Interface Sci., 286, (1), 90-100. DOI: $10.1016 /$ j.jcis.2005.01.007

26. Magdy, Y.H. \& Daifullah, A.A.M.(1998).Adsorption of a basic dye from aqueous solutions onto sugar-industry-mud in two modes of operations. Waste Manage., 18, (4), 219-226. DOI: 10.1016/s0956-053x(98)00022-1.

27. Hameed, B.H., Din, A.T.M. \& Ahmad, A.L.(2007). Adsorption of methylene blue onto bamboo-based activated carbon: Kinetics and equilibrium studies. J. Hazard. Mater., 141, (3), 819-825. DOI: 10.1016/j.jhazmat.2006.07.049.

28. Rui, M.N., Caetano, A.P.F., Seabra, M.P., Labrincha, J.A. \& Pullar, R.C.(2018,).Extremely fast and efficient methylene blue adsorption using eco-friendly cork and paper waste-based activated carbon adsorbents. J. Cleaner Prod. 197, 1137-1147. DOI: $10.1016 /$ j.jclepro.2018.06.278. 
29. Maguana, Y.E., Elhadiri, N., Bouchdoug, M. \& Benchanaa, M. (2018).Study of the influence of some factors on the preparation of activated carbon from walnut cake using the fractional factorial design. J. Environ. Chem. Eng., 6, (1), 1093-1099. DOI: 10.1016/j.jece.2018.01.023.

30. Auta, M. \& Hameed, B.H. (2011).Optimized waste tea activated carbon for adsorption of Methylene Blue and Acid Blue 29 dyes using response surface methodology. J. Cleaner Prod., 175, (8), 233-243. DOI: 10.1016/j.cej.2011.09.100.

31. Dural, M.U., Cavas, L., Papageorgiou, S.K. \& Katsaros, F.K. (2011).Methylene blue adsorption on activated carbon prepared from Posidonia oceanica (L.) dead leaves: Kinetics and equilibrium studies. Chem. Eng. J., 168, (1), 77-85. DOI: 10.1016/j.cej.2010.12.038.

32. Altenor, S., Carene, B., Emmanuel, E., Lambert, J., Ehrhardt, J.J. \& Gaspard, S.(2009). Adsorption studies of methylene blue and phenol onto vetiver roots activated carbon prepared by chemical activation. J. Hazard. Mater., 165, (1), 1029-1039. DOI: 10.1016/j.jhazmat.2008.10.133.

33. Tatycostodes, V.C., Fauduet, H., Porte, C. \& Delacroix, A. (2003).Removal of $\mathrm{Cd}(\mathrm{II})$ and $\mathrm{Pb}$ (II) ions, from aqueous solutions, by adsorption onto sawdust of Pinus sylvestris. J. Hazard. Mater., 105, (1), 121-142. DOI: 10.1016/j.jhazmat.2003.07.009.

34. Bhaumik, R., Mondal, N.K. \& Das, B.(2015).Eggshell Powder as an Adsorbent for Removal of Fluoride from Aqueous Solution: Equilibrium, Kinetic and Thermodynamic Studies. J. Chem., 9, (3), 1457-1480. DOI: 10.1155/2012/790401.

35. Silva, J.P., Sousa, S., Gonçalves, I., Porter, J.J. \& Ferreira-Dias, S.(2004).Modelling adsorption of acid orange 7 dye in aqueous solutions to spent brewery grains. Sep. Purif. Technol., 40, (3), 309-315. DOI: 10.1016/j.seppur.2004.02.006. 